\title{
Meeting Our Students Where They're At: Modeling and Teaching Basic Academic Skills within the College and University Classroom
}

\author{
Sarah Hunter, Cindy Korpatnicki \\ Georgian College, Ontario, Canada
}

\begin{abstract}
This paper is written as an accessible and practical guide that outlines how college and university teachers can embed time management, note taking, and reading skills into their lesson plans without having to sacrifice important course content. This guide is informed by the conversations we had during our workshop at the CICE conference with teachers from a diverse range of countries about the challenges they face with a number of their students who do not possess many of the basic academic skills required to be successful in college and/or university.
\end{abstract}

\section{Introduction}

In June of this year we had the opportunity to present a workshop at the Canadian International Conference on Education (CICE) in Cape Breton, Nova Scotia. Our workshop focused on embedding time management, note taking, and reading skills into the post-secondary classroom. The workshop drew on our experience as Learning Strategist Counselors and Professors at Georgian College in Barrie and Orillia, Ontario where our primary function is to work with students individually and in the classroom setting to teach them how to learn more effectively and more efficiently. Our workshop built on the work started by our colleague, Christina Meredith, who initiated the practice of conducting learning strategies workshops in many courses at our college, becoming so successful, it is now common practice within our Learning Strategy services. Meredith's work was informed by the understanding that students learn academic skills more effectively when these skills are taught within the context of their courses, commonly referred to as embedded learning strategy instruction. Building on this praxis of embedding learning strategies into the classroom, the Learning Strategists from all campuses volunteered to create a learning strategy course for one of our largest foundational programs. This first year, first semester course focuses on building academic skills such as time management, note taking, reading, studying, test taking, group work, information literacy, math, and stress management skills. Due to the success of this course, our college is now working toward embedding learning strategies into most first year first semester courses.
It is our hope that this article encourages other college and university teachers to incorporate some of these much needed learning strategies and basic academic skills into their own classrooms.

\section{Embedding Academic Skills}

Three of the primary tenants of learning strategy instruction are teaching, modeling and practice. In order for students to learn a specific academic skill or strategy, we must first teach the strategy, then model it and finally, give students an opportunity to practice the strategy in class. Although these steps are simple enough, the demands of teaching a specific amount of content leaves teachers with the impression that teaching basic academic skills will take up precious time allotted for lesson delivery. In the following sections on time management, note taking and reading we reflect on our conversations with teachers about the challenges college and university students face with basic academic skills and outline methods to embed these skills into classroom instruction.

\subsection{Time Management}

One of the most challenging skills our postsecondary students experience is the ability to manage their time: ranging from planning their semester, organizing an assignment from start to completion, balancing academics with both full time and part-time work, planning on-line course work, navigating the demands of parenthood with the necessity of homework, living in a new city and certainly balancing social activities with the demands of school. Many of our students, particularly those coming directly from secondary institutions, have never had to manage their time. For non-traditional students (mature, international, parents, etc.) the addition of academics into an already busy life is a new challenge and requires a shift in thinking. Our workshop participants and research confirm that this lack of experience can and most often does manifest itself in increased levels of stress and anxiety, incomplete assignments and homework, lower grades, dissatisfaction with the educational institution, and finally attrition before completion [1]. Effective time management is not only an important survival skill for our students, but it is also an essential employability skill. Making this 
connection when teaching students time management skills is foundational in cultivating their engagement and buy-in. We encourage students to use these tools in their professional portfolios and to reflect on how they can prove to future employers that they have well developed time management skills.

One of the ways our department has worked to mitigate these challenges is to work with faculty in embedding time management skills into first year, first semester courses. Building time management skills into the curriculum offers benefits to both students and faculty. Students experience less stress, learn to balance the demands of school and life, and also learn how to prepare for future careers. Faculty who teach time management notice there are fewer requests for assignment extensions, fewer late assignments, and they have better prepared students. Time management activities can include a semester plan, a weekly plan, assignment breakdown plan, a reading plan, and a daily and/or weekly task list.

One of our most successful and most requested time management tools is the Semester Plan. It is exactly what it sounds like - a plan for the work required for the semester. It is a one-page document with the weeks of the semester listed down the left hand side and the courses the student is taking listed across the top (figure 1). The courses are listed in the order they fall, from Monday to Friday. The students use their syllabi to extract any assignment or test worth a grade and record it into the corresponding week it is due. They will also list how much the assignment or test is worth. The final document will then give the student an at-a-glance reference as to when everything is due, how many items they must complete in a given week, give them an opportunity to plan for those busy weeks, prepare for heavy exam times, and finally, ascertain how much time they should spend on any given assignment or test. Faculty can easily embed this activity in the first week of the semester at the same time that they hand out the syllabus. Students will then have an immediate indication of what their semester will look like. This activity can be done in groups, pairs, or individually. Rich discussion naturally follows about how time must be well managed in post-secondary education.

For further information on how to complete a semester plan, a weekly plan, and a reading plan our college's video tutorials can be found at: http://library.georgiancollege.ca/c.php?g=1240\&p=4 $\underline{246}$ Georgian also welcomes you to direct students to these tutorials.

Another very useful time management tool is the Assignment Breakdown Plan. Participants in our workshop remarked that many students do not know what is involved in breaking down an assignment and consequently do not plan enough time to get it done. We frequently find this in our own practice, when students show up on the day the assignment is due with elevated stress levels. Once taught how to breakdown an assignment, students become more relaxed and well on their way to becoming independent learners. An Assignment Breakdown activity can be done at the same time the teacher hands out an assignment. She/he breaks the class into groups or pairs and asks students to first break the assignment down into tasks and then estimate the time necessary to complete each task. Students should then plot each task into their weekly planner. This activity not only prepares students for their upcoming deadline, but also alerts them to any potential concerns they have with the assignment. The benefits for teachers include having time to clear up any concerns or questions about the assignment, on-time assignments, less stress in the classroom, better-prepared students, and more accomplished student work.

\begin{tabular}{|l|l|l|l|l|l|}
\hline Course & English & Math & Science & Comm & Art \\
\hline Day & Mon & Mon & Wed & Thu & Fri \\
\hline Sep 2-5 & & & & & \\
\hline Sep 8-12 & & Quiz 5\% & & & \\
\hline $\begin{array}{l}\text { Sep 15- } \\
19\end{array}$ & Test 10\% & & & $\begin{array}{l}\text { Assign } \\
15 \%\end{array}$ & \\
\hline $\begin{array}{l}\text { Sep 22- } \\
\text { 26 }\end{array}$ & & & Quiz 5\% & & \\
\hline $\begin{array}{l}\text { Sept 29- } \\
\text { Oct 3 }\end{array}$ & & & & & \\
\hline Oct 6-10 & & $\begin{array}{l}\text { Essay } \\
\text { 25\% }\end{array}$ & & & $\begin{array}{l}\text { Midterm } \\
\text { Exam } \\
25 \%\end{array}$ \\
\hline
\end{tabular}

Figure 1. Semester plan

\subsection{Reading}

Research tells us that across most of North America reading instruction ends as early as the sixth grade [2]. It is assumed that by this point children have developed the skills required to decode words and comprehend the ideas presented in written text. Decoding and basic comprehension lessons equip the young reader with the ability to make meaning of what they read, however, post-secondary faculty at our school and in our workshop lament that students do not bring these skills to college. Our experience as professors and learning strategists reinforces the notion that many post-secondary students are not prepared with the skills and/or strategies required to comprehend advanced material. Many postsecondary professors and instructors assume students have the ability to understand what they read and many express frustrations in their students' inability to commit to the task of reading.

The reading comprehension skills required in postsecondary are different than those of the elementarysecondary system. They require students to make sense of material written in new genres or styles, to 
decipher new vocabularies, to understand complex texts, or to engage with the thoughts and ideas presented in written material that they may consider boring or uninteresting.

As learning strategists, we are committed to supporting students to develop better systems of reading, including a repertoire of strategies to use before, during, and after reading. Research demonstrates that integration of basic academic skills in the form of learning strategies inside the course yields better student work. If teachers can integrate these strategies into their classroom teaching, students are more likely to see their value and practice their application.

A study on college students reading comprehension revealed that when students read an academic text, many believe that they will automatically or intuitively process the text at a deeper level of understanding [3]. In our experience and that of our workshop participants, we know this not to be the case. Many students are not processing their text at a deeper level because they engage in passive, rather than active reading strategies. Participants in our workshop noted how active reading is common practice for good readers. For many this was an "aha” moment, good readers are not born, but rather must be taught to develop strategies in the classroom.

Active engagement compliments good reading. Academics know that good readers ask questions as they read, they re-read often, clarify what they do not understand and most importantly, they synthesize this new information with existing schemas to pose thoughtful questions and engage in higher order thinking. These are the very skills we can cultivate in our own classrooms by teaching our students both content and good reading strategies using the course textbook.

Our work with students tells us that students read by opening their text to the assigned reading and simply beginning. How in a classroom do we rewind this process and teach students how to actively engage with reading prior to beginning? Another common concern is that students struggle to remember what they read. To support both this active engagement and knowledge retention we advocate for the commonly used SQ3R (Survey, Question, Read, Recite, Review) approach [4]. Emphasizing the pre-reading portion of this strategy, survey or skim, is especially useful to students. Relating this to how students process information on a daily basis is helpful. They skim magazines and newspapers to assess their worth prior to purchasing them, skim movie cases to make a decision on a film and skim over loads of online information to pull out what they find useful or catchy. This process of surveying the text before reading allows prior knowledge to be activated and gives the student an essential map of what they are about to read, ultimately improving comprehension.

Building on the principles of the SQ3R, the second step - questioning - is important because it teaches students how to pose thoughtful questions to guide their reading. We have noted through our work with students that after asking questions about material they are more engaged while reading for the answers. This can be simply explained by natural curiosity; we seek the answers to our own questions. Due to the thinking skills required to ask higher order questions we use a q-matrix (figure 2). Teaching students how to use this matrix and ask good questions allows them to independently predict what important information they may be asked on a test or exam. It also helps guide our students away from asking mere factual questions about the text. For example instead of asking, "What is stress?" which could be simply defined with the help of the textbook glossary, this tool could encourage a student to dig a little deeper asking, "How does stress manifest itself in the workplace, in our personal lives, or at school?" Students often remark the sense of liberation they feel when they learn how to predict the "important" questions, creating a sense of confidence that they are indeed reading with the right purpose and are focusing on the information that matters.

The third, fourth, and final step of the SQ3R method - read, recite, and review - builds on knowing the value of modelling effective reading. We encourage teachers to model for students, but we also believe in the importance of letting students observe their peers reading. Reading workshops or group reading can involve students all reading independently, allowing weaker readers to observe the processes of stronger readers, or can allow students to read together, discussing the ideas as they are presented. Encouraging discussion about reading while reading teaches students that reading actively has immense value, and that the thinking does not happen after the reading, but rather that the two occur together and complement each other.

An activity we worked through with participants during our workshop was "Textbook in a Lecture," a reading workshop activity that allows students to read through a small section of their textbook in groups with their peers. This strategy is adapted from a well-known elementary school activity, Novel in an Hour. During novel in an hour small groups are assigned chapters of a novel, after reading their chapter and becoming "experts" the students present back their own sections to the entire class sequentially. In this post-secondary adaptation small groups become experts on sections or entire chapters of their course textbook and culminate their understanding by teaching back their content to the class. This activity allows weaker readers to observe stronger readers, to question and reflect on their own reading processes and to see the value in having a 
well-developed reading practice. As well, the value to students in building their own knowledge is far more beneficial than having the teacher summarize the text. During our CICE workshop participants worked to collaboratively survey and question the challenging reading material they were assigned. They were given the task of reading as a group to prepare to teach back three important or big ideas to the larger group upon completion of their section. Our goal was for teachers to experience the value of this activity prior to incorporating it in their own lectures.

Similar to what we see in our classrooms, we observed our workshop participants helping each other, discussing important details they found in the reading, clarifying misunderstandings, and working together to summarize the most pertinent information in the text. One of the benefits to teachers is that instead of spending time summarizing the text during lecture, we spend our time observing our students and monitoring for understanding. This enhances learning and allows knowledge to be generated within the classroom, leading the teacher to facilitate more and lecture less.

\begin{tabular}{|c|c|c|c|c|c|c|}
\hline & Is & Did & Can & Would & Will & Might \\
\hline What & & & & & & \\
\hline Where & & Factual & & & Predict & \\
\hline When & & & & & & \\
\hline Who & & & & & & \\
\hline Why & & Analytical & & & $\begin{array}{c}\text { Synthesis } \\
\text { and } \\
\text { Application }\end{array}$ & \\
\hline How & & & & & & \\
\hline
\end{tabular}

Figure 2. Q-matrix

Adapted from Bloom's Taxonomy and Mary Anne Patterson, Lambton Kent District School Board

\subsection{Note Taking}

In the literature on college and university note taking, in our experience as Learning Strategist Counselors, and reinforced by the teachers in our workshop, one of the foundational skill challenges our students face in an academic setting is the process of note taking. Teachers related that students are often unsure as to what notes from the lecture are important and how much they should write. Students, teachers said, attempt to write down everything they say, often missing the vital information of the lecture. The second difficulty students face is concentrating on the lecturer, while at the same time, taking effective notes.

Note taking however, is not just about capturing the important information of a lecture; it is also a crucial part of the active learning process [5]. While they are taking their notes, students are involved in "meaning-making and understanding" [6], making cognitive connections to previously learned material and anticipating what information will be needed for future review [7]. Modeling effective note taking helps students organize information, improves learning, helps with studying and test taking, focuses student attention on the lecture, enables students to disseminate important information, and helps with scaffolding complex ideas. Teachers can help students learn to take notes by guiding the note taking process through explanation, example, and modeling. One tried and true method is the Cornell Method of note taking (figure 3) developed by Dr. Walter Pauk of Cornell University.

In this method the paper is divided (figure 3) into 3 sections. The left hand column is used for questions, while the right hand column is used for the answer or the notes from the reading and/or lecture. The questions can be culled from the headings in the textbook or created after the notes are taken. Basically, the students must ask themselves "what questions could my teacher ask me about this information on a test." This process has the added benefit of providing deeper thinking about the information the student has just taken from the lecture. The bottom section is a brief summary of the information contained on this page. Students struggling to pose questions can also be encouraged to use the q-matrix (figure 2) to guide this process.

The teacher can embed this method into their lecture by explaining the method and then using it in their own powerpoint presentation or if they do not use powerpoint, faculty can draw it on the blackboard or provide handouts. For the first lecture the teacher will prepare and provide both the question and answer portion, giving the student an opportunity to see how the method works. As the weeks progress, the teacher will provide fewer questions and answers, turning the responsibility for note taking over to the student, thus gradually scaffolding students to become accountable for their own learning. This method helps students study for tests by having practice test questions fully prepared well in advance of studying, improving their buy-in. 


\begin{tabular}{|l|l|}
\hline $\begin{array}{l}\text { Questions } \\
\text { (Or Main Idea) }\end{array}$ & $\begin{array}{l}\text { Answer } \\
\text { (Or Supporting Details) }\end{array}$ \\
\hline \hline $\begin{array}{l}\text { What are some of the } \\
\text { ways I can model/use } \\
\text { effective note taking } \\
\text { in my lecture? }\end{array}$ & $\begin{array}{l}\text { 1. Provide students with the questions that will be } \\
\text { answered in lecture. This will help students focus on } \\
\text { important/relevant information } \\
\text { 2. Model effective note taking through your } \\
\text { powerpoints. } \\
\text { 3. Create activities for your students using various note } \\
\text { taking activities as the organizing structure for more } \\
\text { complex information that students must learn. }\end{array}$ \\
& $\begin{array}{l}\text { Example: Create a group mind mapping activity on a } \\
\text { concept, process, a chapter in the textbook, historical } \\
\text { significance of events, compare and contrast, sequence } \\
\text { of events, etc. }\end{array}$ \\
\hline $\begin{array}{l}\text { Summary } \\
\text { Modeling effective note taking }\end{array}$ \\
\hline
\end{tabular}

Figure 3. Cornell method note taking

Teachers, however, need not limit their example of note taking to one single method. Depending on the subject matter, note taking can include mind mapping, charts, outlining, and subject specific methods like the 3-column math problem solver or the Frayer Model (figure 4). In the Frayer model [8], the main idea or terminology is placed in the center, while the definition, facts/characteristics, examples, and non-examples are placed in the four corners. Teachers can change these categories to suit their specific subject area and create in-class learning activities around challenging concepts or topics.

Although brief, we hope this article functions as a springboard for college and university teachers to create their own learning strategy activities for their unique learning environments.

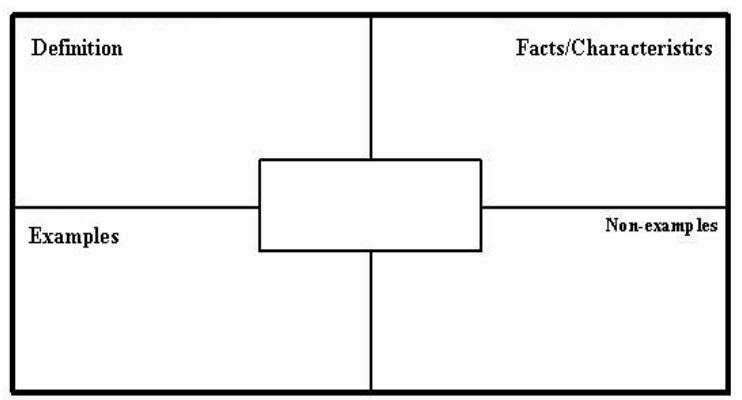

Figure 4. Frayer model

\section{Acknowledgements}

We would like to recognize the knowledge and support of our colleagues from all campuses in the Academic Success Centre, with special thanks to Katherine Wallis, Christina Meredith, and the Georgian College Centre for Teaching and Learning.

\section{References}

[1] Forbus, P., Newbold, J. J., \& Mehta, S. S. "A Study Of Non-Traditional And Traditional Students In Terms Of Their Time Management Behaviors, Stress Factors, And
Coping Strategies”, Academy Of Educational Leadership Journal, 15. 2011, pp.109-125.

[2] White, H. "Nursing instructors must also teach reading and study skills", Reading Improvement, 41. 2004, pp 3850 .

[3] Linderholm, Tracy., \& Wilde, Adam. "Students' beliefs about comprehension when reading for different purposes”, Journal of College Reading and Learning, 40 (2), Spring 2010, pp. 1-19.

[4] Robinson, F. P. Effective study (Rev. ed.). New York: Harper \& Row, 1961.

[5] Maydosz, A., \& Raver, S. A. "Note taking and university students with learning difficulties: What supports are needed?", Journal Of Diversity In Higher Education, 3(3), 2010, pp. 177-186.

[6] Van der Meer, J. “Students’ note-taking challenges in the twenty-first century: considerations for teachers and academic staff developers", Teaching In Higher Education, 17(1), 2012, pp. 13-23.

[7] Maydosz, A., \& Raver, S. A. "Note taking and university students with learning difficulties: What supports are needed?”, Journal Of Diversity In Higher Education, 3(3), 2010, pp. 177-186.

[8] Frayer, D., Frederick, W. C., and Klausmeier, H. J. A, Schema for Testing the Level of Cognitive Mastery. Wisconsin Center for Education Research, Madison, Wisconsin, 1969. 